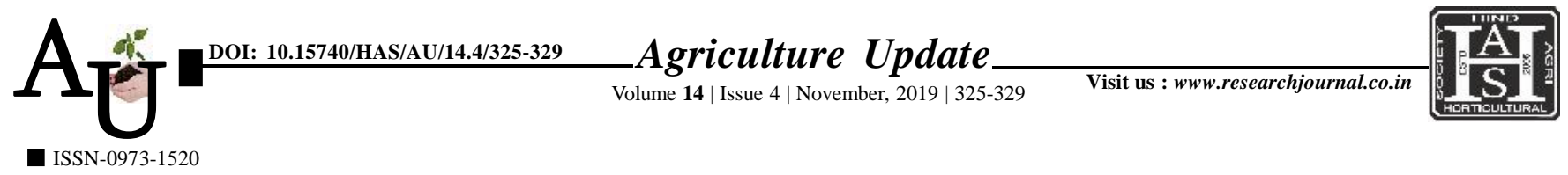

\title{
Research Article: Content analysis of Agrowon daily with special reference to horticulture information
}

Article Chronicle: Received : 09.07.2019;

Revised : 16.10.2019;

Accepted :

23.10.2019

KeY Words:

Content analysis, Agrowon, Horticultural informaton, Space, Page, Side, Illustration
SUMMARY : The Agrowon is the most popular Marathi daily Agricultural newspaper it provides lot of agricultural information in the form of news story, success story, regular agricultural feature, agricultural article and information about different advanced technology cultivation practices and diseases resistant variety. So Agrowon is helpful to farmers to inhance their production. Farmers are early in adopting the new technology by reading Agrowon as compare to other source of agricultural infomation. Therefore, Agrowon play a vital role in changing farmers adoption level and increasing production. So there is need to do content analysis of Agrowon to compare the type of information i.e. Horticultural and nonHoticultural published in Agrowon. Present study consist of location, space covered by the horticultural information and identification of different types, forms of presentation of horticultural information of Agrowon daily published in Marathi daily newspaper 'Agrowon' from Nagpur edition of Maharashtra.52 issues of 'Agrowon' published from 1 January 2018 to 31 December 2018 was selected and studied with the help of specially designed proforma for collection and analysis of the contents of 'Agrowon'. The data was presented in the form of percentage and frequencies. The results of the present investigation are as follows. The non-horticultural information occupied very large space 85.88 per cent as compare to horticultural information 14.11 per cent. Regarding the newspaper advertisements, 14.30 per cent of the total space was occupied by the horticultural advertisements whereas; non-horticultural advertisements occupied very large space i.e. 85.69 per cent. Most of the horticultural information published on right side 53.05 per cent of the newspaper. Most of the horticultural information is in the photo news i.e. 88.55 per cent. Most of the horticultural information printed on page number 12,13,10, and 6.

How to cite this article : Suryvanshi, V.N., Mokhale, S.U., Ade, A.S. and Tayde, R.V. (2019). Content analysis of Agrowon daily with special reference to horticulture information. Agric. Update, 14(4): 325-329; DOI : 10.15740/HAS/AU/14.4/325-329. Copyright@ 2019: Hind Agri-Horticultural Society.
Author for correspondence :

S.U. Mokhale Department of Extension Education, Shri Shivaji Agriculture College, Amaravati (M.S.) India

Email:shekharmokhale17 @ gmail.com

See end of the article for authors' affiliations 